\title{
Research on the Path of Cooperative Development between Urban Carbon Emission and "Population- Energy-Economy" in Beijing
}

\author{
Liu Chunmei \\ Economics and Management College \\ Shandong Jiaotong University \\ Jinan, China \\ Liu6688h@163.com
}

\begin{abstract}
Using System Dynamics, it analyzed the influences of carbon emissions in the aspects of "population-energyeconomy" qualitatively. Then calculated Beijing's carbon emissions quantity based on the energy consumption. Though improved model of relationship of "population-energy-economic" to carbon emissions, it analyzed the regression relationship and different affection of "population-energy-economy" on carbon emissions by the related data in 1980-2014. The impulse response function analysis shows that giving an impact to independent index showed that the effect of changes in the total energy consumption is greater than the other elements in short term. Finally, some suggestions are put forward for the citizen lowcarbon cooperative development.
\end{abstract}

Keywords-Cooperative development; carbon emission; population-energy-economy; Beijing

\section{INTRODUCTION}

Coordinated development of Climate change, population growth, energy saving and economic is the main theme of the world development. the new type of urbanization makes the urban population scale expansion, rapid development in economic, energy consumption and environmental pollution. As energy consumption and carbon emissions of large households, urban becomes the key to the construction of low carbon city. Therefore, it is the inevitable choice and the focus on the sustainable urban development mode in the perspective of "population-energy- economy".

As the capital in China, Beijing's resident population increased by12.8 million from 1978 to 2014 and the urbanization rate is $86.4 \%$. GDP rose by 2.12 trillion Yuan from 1978 to 2014. As a driving force for the development of population and economy, the energy consumption in Beijing has increased rapidly. The fossil energy consumption accounts for about $90 \%$, in which the high emission of coal consumption accounts for about $70 \%{ }^{[1]}$. According to IEA statistics, carbon emissions caused by fossil energy consumption has exceeded the United States in 2007. So, it has a certain practical and theoretical significance to explore

\footnotetext{
Projects:(1) Shandong Provincial Education Department project (J16YF12);

(2) Jinan philosophy and social science project (JNSK16D18);

(3) Shandong Provincial Statistical research project (KT15137);

(4) Shandong Jiaotong University project (JY201413).
}

the collaborative development mode and the issue of carbon emission in the perspective of population, energy consumption and economic development.

\section{LITERATURE REVIEW}

There are many achievements about the population, energy, economy and carbon emissions from Domestic and foreign scholars. York, Rose and $\operatorname{Dietz}(2003)^{[2]}$ analysis the relationship among carbon emissions, population, energy and urban, pointed out that population has a single way effect on carbon emissions by the STIRPAT model. Richmond AK and Kaufmann $\mathrm{RK}(2006)^{[3]}$ analyzed the relationship between income and energy use or carbon emissions. They indicated that whether there is a turning point in the relationship between economic activity and energy use and carbon emissions dependent on fuel mix, the specification for income, and the level of economic development. Mellon H. (2012) ${ }^{[4]}$ analysis comparatively the influence factors of carbon emissions in the perspectives of energy, population and the environment between Canada and other national and consider that the influence of the factors of carbon emissions include population growth, fossil fuel consumption in Canada. Liddle B. (2013) ${ }^{[5]}$ summarized the way demographic factors to influence carbon emissions and energy consumption, which include population, age structure, household size, urbanization, and population density. And considered that urbanization appears positively associated with energy consumption and carbon emissions. Higher population density is associated with lower levels of energy consumption and emissions. Wang Feng(2010) ${ }^{[6]}$ considered the main positive factors of emissions are per capita CDP, number of vehicle, total population, economic structure and average household income and the respective average contributions are $15.82 \%, 4.93 \%$, $1.28 \%, 1.14 \%$ and $1.11 \%$. While the negative factors are energy intensity of production sector, transportation routes length per vehicle, household energy intensity, and the contributions are $-8.12 \%,-3.29 \%$, and $-1.42 \%$. 


\section{QUALITATIVE AND QUANTITATIVE ANALYSIS}

\section{A. The Analysis by System Dynamics}

Recently, rapid economic development, new urbanization and the increase of per capita income level made city lift gathered and demand increased. Consumer demand growth need housing, traffic and infrastructure, and this increase energy consumption. The irrational energy structure and lack of supply side of infrastructure increased emissions and environmental problems.

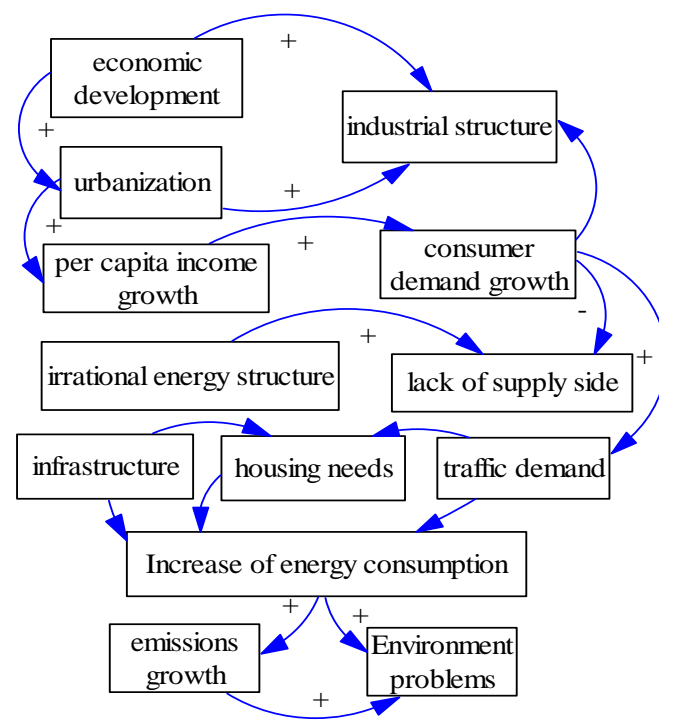

Fig. 1. Causal in Influence factors of carbon emissions

\section{B. Improved STIRPAT model analysis}

The classic model of environmental impact (IPAT) is that the environmental impact(I) and population (P), economic (A) and technology (T). Dietz and Rose constructed STIRPAT (Stochastic Impacts by Regression on Population, Affluence and Technology) model by IPAT.

- $I_{t}=a P_{t}^{\alpha} A_{t}^{\beta} T_{t}^{\gamma} \mu_{t}$

- Improved model(1) to the "population-energyeconomy" model(2), to study the effect factors of carbon emission in Beijing, then give logarithm to both sides (3), that is:

$$
C_{t}=a P_{1 t}^{\alpha_{1}} P_{2 t}^{\alpha_{2}} E_{1 t}^{\beta_{1}} E_{2 t}^{\beta_{2}} G_{1 t}^{\gamma_{1}} G_{2 t}^{\gamma_{2}} \mu_{t}
$$

- $\quad \ln C_{1}=\ln a+\alpha_{1} \ln P_{1 t}+\alpha_{2} \ln P_{2 t}+\beta_{1} \ln E_{t t}+\beta_{2} \ln E_{2 t}+\gamma_{1} \ln G_{t}+\gamma_{2} \ln G_{z_{t}}+\ln \mu_{t}(3)$

- In model(2)and (3), $\mathrm{C}$ is for carbon emissions. $a_{\text {is a }}$ constant. $P_{1}, P_{2}$ are for population, the urbanization rate. $E_{1}, E_{2}$ are for energy consumption, energy consumption structure. $G_{1}, G_{2}$ are for the amount of economic growth, economic structure.

$$
\begin{aligned}
& \alpha_{1}, \alpha_{2}, \beta_{1}, \beta_{2}, \gamma_{1} \text { and } \gamma_{2} \text { are for elasticity } \\
& \text { coefficient of } P_{1}, P_{2}, E_{1}, E_{2}, G_{1} \text { and } G_{2} \mu, t \text { are } \\
& \text { for random error term and time. }
\end{aligned}
$$

\section{Calculating the emissions of Beijing}

At present, More than 95\% of the global carbon emissions came from the fossil fuels burning. So, the emissions can be estimated based on the energy consumption and emission factors. Refer to the "2006 IPCC Guidelines for National Greenhouse Gas Inventories", "Provincial Greenhouse Gas

\begin{tabular}{|c|c|c|c|c|c|c|c|}
\hline Year & C & P1 & E1 & G1 & $\mathrm{P} 2$ & E2 & G2 \\
\hline 1980 & 4757 & 904 & 1908 & 139 & 58 & 72 & 27 \\
\hline 1981 & 4744 & 919 & 1903 & 139 & 58 & 73 & 29 \\
\hline 1982 & 4788 & 935 & 1920 & 155 & 58 & 74 & 29 \\
\hline 1983 & 4949 & 950 & 1985 & 183 & 59 & 74 & 32 \\
\hline 1984 & 5346 & 965 & 2144 & 217 & 59 & 75 & 33 \\
\hline 1985 & 5514 & 981 & 2211 & 257 & 60 & 76 & 33 \\
\hline 1986 & 5984 & 1028 & 2400 & 285 & 60 & 76 & 35 \\
\hline 1987 & 6173 & 1047 & 2476 & 327 & 61 & 76 & 37 \\
\hline 1988 & 6514 & 1061 & 2613 & 410 & 61 & 76 & 37 \\
\hline 1989 & 6615 & 1075 & 2653 & 456 & 62 & 76 & 36 \\
\hline 1990 & 6756 & 1086 & 2710 & 501 & 73 & 76 & 39 \\
\hline 1991 & 7161 & 1094 & 2872 & 599 & 74 & 76 & 44 \\
\hline 1992 & 7449 & 1102 & 2988 & 709 & 74 & 76 & 45 \\
\hline 1993 & 8140 & 1112 & 3265 & 886 & 75 & 75 & 47 \\
\hline 1994 & 8442 & 1125 & 3386 & 1145 & 75 & 75 & 49 \\
\hline 1995 & 8810 & 1251 & 3533 & 1508 & 76 & 75 & 53 \\
\hline 1996 & 9311 & 1259 & 3735 & 1789 & 76 & 74 & 56 \\
\hline 1997 & 9273 & 1240 & 3719 & 2077 & 76 & 71 & 59 \\
\hline 1998 & 9495 & 1246 & 3808 & 2377 & 77 & 71 & 62 \\
\hline 1999 & 9740 & 1257 & 3907 & 2679 & 77 & 71 & 63 \\
\hline 2000 & 10332 & 1364 & 4144 & 3162 & 78 & 69 & 65 \\
\hline 2001 & 10545 & 1385 & 4229 & 3708 & 78 & 68 & 67 \\
\hline 2002 & 11061 & 1423 & 4436 & 4315 & 79 & 69 & 69 \\
\hline 2003 & 11590 & 1456 & 4648 & 5007 & 79 & 70 & 69 \\
\hline 2004 & 12815 & 1493 & 5140 & 6033 & 80 & 70 & 68 \\
\hline 2005 & 13768 & 1538 & 5522 & 6970 & 84 & 72 & 70 \\
\hline 2006 & 14721 & 1601 & 5904 & 8118 & 84 & 72 & 72 \\
\hline 2007 & 15671 & 1676 & 6285 & 9847 & 84 & 73 & 74 \\
\hline 2008 & 15776 & 1771 & 6327 & 11115 & 85 & 72 & 76 \\
\hline 2009 & 16382 & 1860 & 6570 & 12153 & 85 & 72 & 76 \\
\hline 2010 & 17339 & 1962 & 6954 & 14114 & 86 & 69 & 76 \\
\hline 2011 & 17442 & 2019 & 6995 & 16252 & 86 & 70 & 77 \\
\hline 2012 & 17896 & 2069 & 7178 & 17879 & 86 & 69 & 77 \\
\hline 2013 & 16765 & 2115 & 6724 & 19801 & 86 & 67 & 78 \\
\hline 2014 & 17033 & 2152 & 6831 & 21331 & 86 & 66 & 78 \\
\hline
\end{tabular}
Emission Inventory Guidebook" et al. According to energy consumption and carbon emission factors $(\mathrm{EF})^{[7]}$ to calculate.

TABLE I. CARBON EMISSIONS AND “PEOPLE-ENERGY-ECONOMIC”

notes: the unit of C1,P1,E1,G1 are 10 thousand tons,10 thousand persons, 10 thousand tons, 100 thousand Yuan.

The unit of P2,E2,G2 are \%.

data sources: Statistical yearbook of China, Statistical yearbook of Beijing, 2015.

$\mathrm{EF}$ is 0.67 which is from the report of Energy Research Institute National Development and Reform Commission. 


\section{Empirical analysis}

To avoid spurious regression unstable caused by timeseries, it logarithm each variables

$\left(\ln C, \ln P_{1}, \ln P_{2}, \ln E_{1}, \ln E_{2}, \ln G_{1}, \ln G_{2}\right)$ used ADF test (Augmented Dickey-Fuller Test, ADF). The results showed that the statistic ADF of test $t$ of the variables are greater than the significance level of the $t$ statistic, and the corresponding probability $\mathrm{P}>10 \%$. Therefore the variables have unit roots and are non-stationary, and first-order difference sequence have smoothness. So, the variables are integrated of order one sequence, meet premise regression.

Based on Dietz's IPAT and improved STIRPAT, $\ln C$ is the dependent variable, and

$\ln P_{1}, \ln P_{2}, \ln E_{1}, \ln E_{2}, \ln G_{1}, \ln G_{2}$ are the independent variables. The regression analysis results are the formula:

- $\ln C=1.2345+0.0069 \ln P_{1}+0.9367 \ln E_{1}+0.0226 \ln G_{1}+0.0025 \ln P_{2}$ $+0.1047 \ln E_{2}-0.0266 \ln G_{2}$

$R^{2}=99.9 \%, D . W .=2.24, F=44676$

$\mathrm{P}=99.9 \%$ showed that the regression fit well. Therefore, the improved STIRPAT model is significant statistically. The analysis concluded that the impact of energy and its structure is more significant than the other variables.

To analysis the dynamic influence of dependent variables when independent variables subjected to some kind of shock, it select impulse response function (IRF) method.

$\left\{\begin{array}{l}x_{t}=a_{1} x_{t-1}+a_{2} x_{t-2}+b_{1} y_{t-1}+b_{2} y_{t-2}+\varepsilon_{1 t} \\ y_{t}=c_{1} x_{t-1}+c_{2} x_{t-2}+d_{1} y_{t-1}+d_{2} y_{t-2}+\varepsilon_{1 t}\end{array}, t=1,2, \cdots, T\right.$

Among them, $a_{i}, b_{i}, c_{i}, d_{i}$ is the parameter. Assumed that the disturbance $\varepsilon_{t}=\left(\begin{array}{c}\varepsilon_{1 t} \\ \varepsilon_{2 t}\end{array}\right)$ is white noise sequence, the system started from $0, x_{-1}=x_{-2}=y_{-1}=y_{-2}=0$. When $t=0, x_{0}=1, y_{0}=0$ and when $t=1, x_{1}=a_{1}, y_{1}=c_{1}$ and when $t=2, x_{2}=a_{1}^{2}+a_{2}+b_{1} c_{1} y_{2}=c_{1} a_{1}+c_{2}+d_{1} c_{1}$.

When administered to population( $\ln \mathrm{P} 1)$,urbanization (lnP2),energy consumption (lnE1), energy consumption structure (lnE2), economic growth (lnG1) and economic structure (lnG2) a positive impact of unit size, the Carbon emission $(\ln C)$ impulse response function figure as fig.2.

The horizontal axis represents the impact lag period, and the vertical axis represents responsiveness. The solid line represents the response of $\ln C$ to the impact of the corresponding elements. Fig.2. shows that when give a impact to $\ln P(\ln P 1, \ln P 2), \ln E(\ln E 1, \ln E 2), \ln G(\ln G 1, \ln G 2)$, it will cause fluctuations in $\operatorname{lnC}$, and the fluctuation will reduce over time gradually. Comparison of pulse response function of $\ln P$, $\ln E$, $\ln G$ based on no considering the influence of $\ln C$ itself, which showed that the effect of changes in $\ln E$ is greater than the other elements in short term.

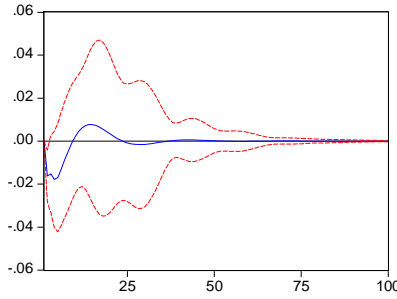

a. Response of $\ln C$ to $\ln E_{1}$

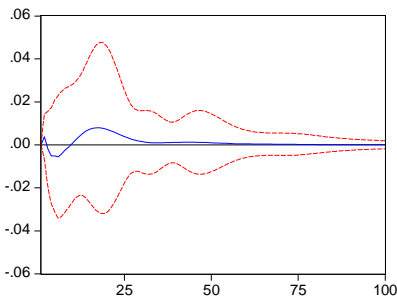

c. Response of $\ln C$ to $\ln G_{1}$

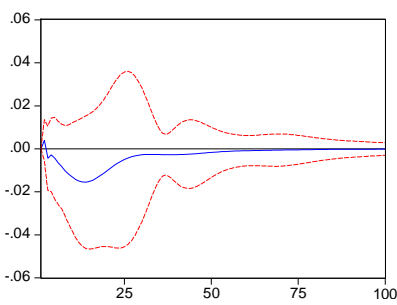

e. Response of $\ln \mathrm{C}$ to $\ln \mathrm{P}_{1}$

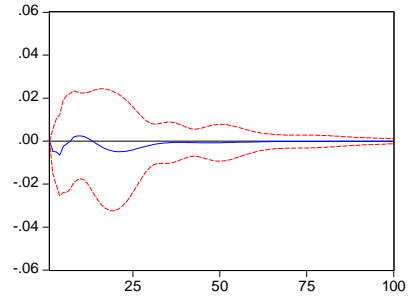

b. Response of $\ln C$ to $\ln E_{2}$

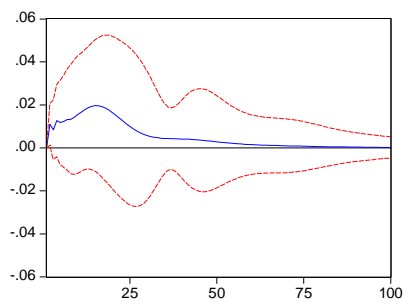

d. Response of $\ln C$ to $\ln G_{2}$

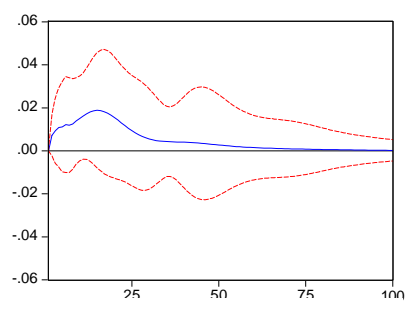

f. Response of $\ln C$ to $\ln \mathrm{P}_{2}$
Fig. 2. Response of $\ln C$ to $\ln P, \ln E, \ln G$,

\section{CONCLUSIONS AND SUGGESTIONS}

\section{A. Conclusions}

Overall, population-energy-economy has a significant impact on carbon emissions, but it is different for various factors.

1) Energy. Affected factors of carbon emissions arranged in order: energy consumption > Energy Structure > economy> Total population $>$ urbanization rate $>$ economic structure.

2) Economic.Energy is directly related to carbon emissions, but energy consumption is impacted by economic growth, and the industrial structure is impacted the energy consumption structure in the long term.

3) Population.the impacted Coefficient of total population and urbanization on carbon emissions are 0.69\%, $0.25 \%$, indicats that the population growth promots the carbon emissions but not obviously.

\section{B. Suggestions}

With the rapid development of urban economy and urbanization, energy consumption, Energy consumption grew fast. It lead to a sharp increase in carbon emissions. Therefore, It has a certain practical significance based on the Perspective of population-Energy-Economic. According to the analysis, in 
order to further promote low-carbon growth, recommendations the following:

1) Reduce energy consumption, and adjusting energy structure.

Total energy consumption, especially coal accounts for the proportion of total energy consumption is a key factor in the growth of carbon emissions. Therefore, to control carbon emissions to achieve a low-carbon development, must control the total energy consumption, adjust the coal-dominated energy structure, increase the proportion of green energy in total energy consumption, to achieve green energy development.

2) coordinated and equilibrium the relationship between low-carbon and economy, adjust the industrial structure actively.

To reduce carbon emissions to achieve a low-carbon development, it should balance low-carbon and economic development. So it must ensure less impact on economic development under the conditions of the current economic downward pressure. Furthermore, it is a negative correlation between industrial structure and carbon emissions. The optimization and upgrading of industrial structure lead to economic growth while reducing carbon emissions. Therefore, upgrading the industrial structure is a priority to reduce carbon emissions.

3) Regulated the total population of mega-cities and the urbanization rate.

Economic growth is inseparable from the people gathered, while the population gathered promote economic growth and bring pressure to low-carbon urban development. Especially population of Beijing is over 10 million, it is a megacity. Large urban population is one of the main factors in the growth of carbon emissions. To control carbon emissions in Beijing, it must regulate urban population growth reasonably.

\section{Acknowledgment}

Thanks are due to my supervisor, Professor Duan, for a lot of valuable discussion, which make me explore the good direction not only in this thesis but also in my future study. I shall extend my thanks to some projects that cause me work hard, that is footnoted on the first page.

\section{References}

[1] Beijing Bureau of statistics. Beijing Statistical Yearbook [M]. China statistical Publishing, 2015

[2] York R, Rosa E A, Dietz T. STIRPAT, IPAT and ImPACT: analytic tools for unpacking the driving forces of environmental impacts[J]. Ecological Economics, 2003, 46(3):351-365.

[3] Richmond A K, Kaufmann R K. Is there a turning point in the relationship between income and energy use and/or carbon emissions?[J]. Ecological Economics, 2006, 56(2):176-189.

[4] D Kerr, H Mellon. Energy, population and the environment: exploring Canada's record on $\mathrm{CO}_{2}$ emissions and energy use relative to other OECD countries [J]. Population \& Environment, 2012, 34(34):257-278.

[5] Liddle, Brantley. Impact of population, age structure and urbanization on carbon emissions, energy consumption: Evidence from macro-level, cross-country analyses [J]. Population and Environment, 2013, 35(3): 286-304.

[6] Wang Feng, Wu Lihua and Yang Chao. Driving Factors for Growth of Carbon Dioxide Emissions During Economic Development in China[J]. Economic research, 2010(2):123-135

[7] IPCC. http://www.ipcc-nggip.iges.or.jp/public/2006gl/chinese/2006. 